\title{
The Irminger Sea and the Iceland Sea time series measurements of sea water carbon and nutrient chemistry 1983-2008
}

\author{
J. Olafsson ${ }^{1,2}$, S. R. Olafsdottir ${ }^{1}$, A. Benoit-Cattin ${ }^{1}$, and T. Takahashi ${ }^{3}$ \\ ${ }^{1}$ Marine Research Institute, Skulagata 4, IS 121 Reykjavik, Iceland \\ ${ }^{2}$ Institute of Earth Sciences, University of Iceland, Sturlugata 7, IS 101 Reykjavik, Iceland \\ ${ }^{3}$ Lamont-Doherty Earth Observatory, Palisades, NY 10964, USA
}

Received: 23 September 2009 - Published in Earth Syst. Sci. Data Discuss.: 16 October 2009

Revised: 4 March 2010 - Accepted: 5 March 2010 - Published: 15 March 2010

\begin{abstract}
This paper describes the ways and means of assembling and quality controling the Irminger Sea and Iceland Sea time-series biogeochemical data which are included in the CARINA data set. The Irminger Sea and the Iceland Sea are hydrographically different regions where measurements of sea water carbon and nutrient chemistry were started in 1983 . The sampling is seasonal, four times a year. The carbon chemistry is studied with measurements of the partial pressure of carbon dioxide in seawater, $p \mathrm{CO}_{2}$, and total dissolved inorganic carbon, $\mathrm{TCO}_{2}$. The carbon chemistry data are for surface waters only until 1991 when water column sampling was initiated. Other measured parameters are salinity, dissolved oxygen and the inorganic nutrients nitrate, phosphate and silicate. Because of the CARINA criteria for secondary quality control, depth $>1500 \mathrm{~m}$, the IRM-TS could not be included in the routine QC and the IS-TS only in a limited way. However, with the information provided here, the quality of the data can be assessed, e.g. on the basis of the results obtained with the use of reference materials.
\end{abstract}

\section{Data coverage and parameter measured}

Repository-Reference: doi:10.3334/CDIAC/otg.CARINA.AMS.V1.2

doi:10.3334/CDIAC/otg.CARINA.ATL.V1.0

Available at: http://cdiac.ornl.gov/oceans/CARINA/Carina_inv.html

Coverage: $64^{\circ} \mathrm{N}-68^{\circ} \mathrm{N} ; 28^{\circ} \mathrm{W}-12^{\circ} \mathrm{W}$

Location Name: Irminger Sea and Iceland Sea

Date/Time Start: 1983-03-05

Date/Time End: 2006-02-10 


\begin{tabular}{|c|c|c|c|c|}
\hline $\begin{array}{l}\text { Data Product } \\
\text { Parameter Name }\end{array}$ & $\begin{array}{l}\text { Data Product } \\
\text { Flag Name }\end{array}$ & $\begin{array}{l}\text { Exchange File } \\
\text { Parameter Name }\end{array}$ & $\begin{array}{l}\text { Exchange File } \\
\text { Flag Name }\end{array}$ & Units \\
\hline station & & STANBR & & \\
\hline day & & DATE & & \\
\hline month & & DATE & & \\
\hline year & & DATE & & \\
\hline latitude & & LATITUDE & & decimal degrees \\
\hline longitude & & LONGITUDE & & decimal degrees \\
\hline depth & & DEPTH & & meters \\
\hline temperature & & CTDTMP & & ${ }^{\circ} \mathrm{C}$ \\
\hline salinity & sf & SALNTY & SALNTY_FLAG_W & \\
\hline ctdsal & ctdsf & CTDSAL & CTDSAL_FLAG_W & \\
\hline pressure & & CTDPRS & & decibars \\
\hline oxygen & of & OXYGEN & OXYGEN_FLAG_W & micromole $\mathrm{kg}^{-1}$ \\
\hline nitrate & no3f & NITRAT & NITRAT_FLAG_W & micromole $\mathrm{kg}^{-1}$ \\
\hline silicate & sif & SILCAT & SILCAT_FLAG_W & micromole $\mathrm{kg}^{-1}$ \\
\hline phosphate & po4f & PHSPHT & PHSPHT_FLAG_W & micromole $\mathrm{kg}^{-1}$ \\
\hline tco2 & tco2f & TCARBN & TCARBN_FLAG_W & micromole $\mathrm{kg}^{-1}$ \\
\hline \multirow[t]{2}{*}{ microatm } & & $\mathrm{PCO} 2$ & PCO2_FLAG_W & microatm \\
\hline & & PCO2_TMP & & ${ }^{\circ} \mathrm{C}$ \\
\hline
\end{tabular}

For a complete list of all parameters available in CARINA see Key et al. (2009). Note the different names for the parameters in the Exchange files (the individual cruise files) and the merged data product.

\section{Introduction}

In 1983 a study of the seasonal variability of carbon-nutrient chemistry was initiated off the Iceland shelf in two hydrographically different regions of the northern North Atlantic (Takahashi et al., 1985; Peng et al., 1987). One station was in the northern Irminger Sea (IRM-TS) with relatively warm and saline $(S>35)$ Modified North Atlantic Water derived from the North Atlantic Drift. This location may also be described as representing the sub-polar gyre (Hátún et al., 2005b). The other station was in the Iceland Sea (IS-TS) where cold Arctic Intermediate Water, formed from Atlantic Water and low salinity Polar Water usually predominates but the Polar Water influence in the surface layers is variable (Stefánsson, 1962; Hansen and Østerhus, 2000). Both stations are thus in regions important as sources for North Atlantic Deep Water (NADW). The original seasonal variability study was expanded in time and the sampling incorporated into the quarterly cruises of the repeat hydrography network of the Marine Research Institute (MRI) in Reykjavik, Iceland. Quarterly sampling is insufficient to adequately describe annual biochemical processes in these waters. It has, however, been estimated, with respect to hydrographic variability in sub-arctic waters of the N-Atlantic, that 4 observations/year are sufficient to record decadal variability (Hátún et al., 2005a). The Iceland Sea time series data has recently been evaluated to describe the rate of seawater acidification, at surface and deep levels (Olafsson et al., 2009). The time series observations have been carried out under the EC projects ESOP-2, TRACTOR and currently CARBOOCEAN and EPOCA.

\section{Data provenance}

The CARINA database includes data and metadata from 188 oceanographic cruises/campaigns, of which five entries consist of multiple cruises (Key et al., 2009). The IS and IRM time series contribute to the CARINA data. However, since these stations are in relatively shallow locations compared to the CARINA secondary quality control criteria, depth $>1500 \mathrm{~m}$ and considering also the high temporal variability, IRM-TS could not be included in the secondary QC. Data from the IS-TS is however included in the secondary QC for $\mathrm{TCO}_{2}$ and nutrients as described in Olsen (2009) and Olafsson and Olsen (2010). Here we describe the methods and quality control procedures applied in gathering the two time series data sets. The IRM-TS is included in the CARINA-ATL region (Tanhua et al., 2010) and the IS-TS is included in the CARINA-AMS region (Olsen et al., 2009).

The repeat hydrography network of the Marine Research Institute (MRI) is carried out in quarterly cruises conducted generally in February, May, August and November each year. The time series stations are located at $64.33^{\circ} \mathrm{N}, 28.0^{\circ} \mathrm{W}$ (IRM-TS) where the depth is $1000 \mathrm{~m}$ and the IS-TS station is at $68.0^{\circ} \mathrm{N}, 12.67^{\circ} \mathrm{W}$ where the depth is $1850 \mathrm{~m}$ (Fig. 1). When it has not been possible to reach the time series location but observations have been available at a nearby station in the region, these have been incorporated into the time series. The nearby stations are generally within $70 \mathrm{~km}$ from the time series location except in 1983-1984 when the initial Iceland Sea sampling was $250 \mathrm{~km}$ to the west of the fixed location. 


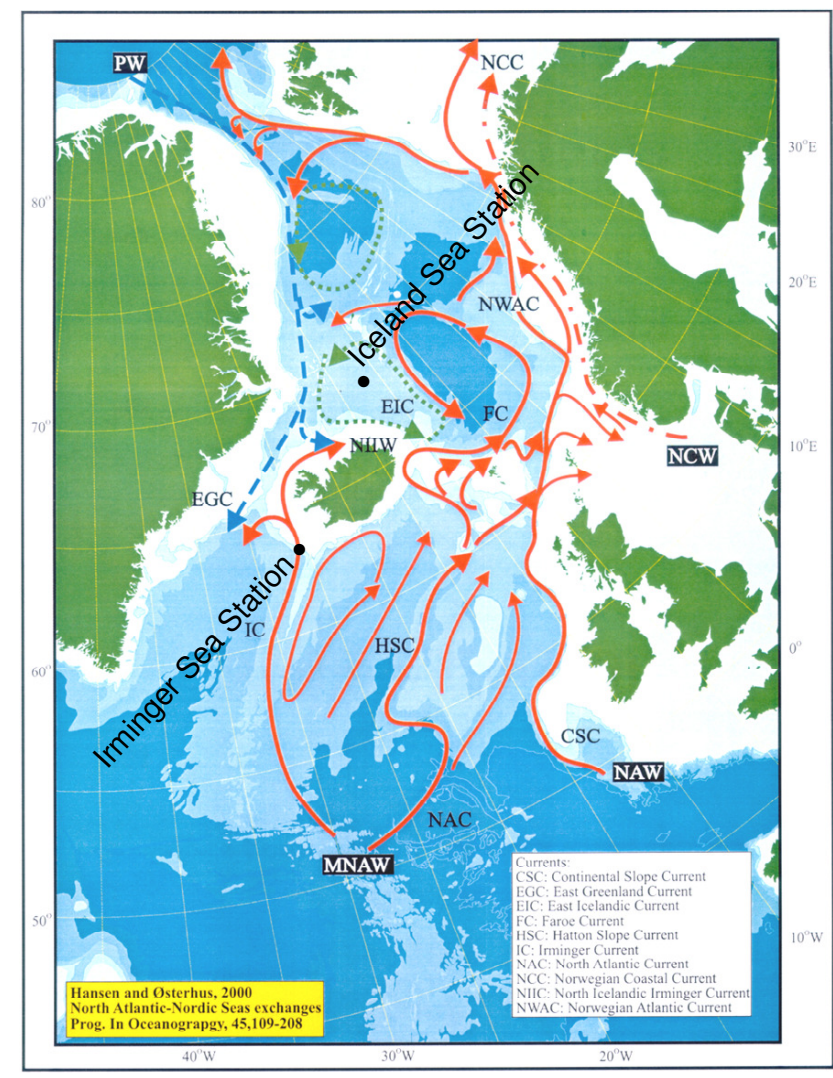

Figure 1. Locations of the Irminger Sea and the Iceland Sea time series stations inserted on the N-Atlantic surface current chart of Hansen and Østerhus (2000).

Samples from all collection depths have been taken for salinity, dissolved oxygen and inorganic nutrients. From 1983 to 1991 only surface samples for $p \mathrm{CO}_{2}$ and $\mathrm{TCO}_{2}$ were collected. Water column sampling for $\mathrm{TCO}_{2}$ started in 1991 and for $p \mathrm{CO}_{2}$ in 1993.

\section{Methods and quality control procedures}

\subsection{Hydrography}

From 1983 to the end of 1989 the station water sampling was conducted with TPN-Nansen water bottles, from HYDROBIOS GmbH, on a hydrowire. They were fitted with reversing mercury thermometers. From the beginning of 1990 the station work has been conducted using SEA-BIRD Conductivity-Temperature-Depth (CTD) profiling instruments and water bottles on a rosette. Sample salinity measurements were carried out using Guildline Autosal Model 8400 salinometers.

\subsection{Dissolved oxygen}

Dissolved oxygen has been determined throughout the time series by an in-bottle microburette Winkler titration and visual end point detection (Carpenter, 1965). The sample bottles are volume calibrated Quickfit brand Erlenmeyer type of $50 \mathrm{ml}$ nominal volume.

\subsection{Inorganic nutrients}

Samples for the determinations of the phosphate, nitrate (nitrate+nitrite) and silicate concentrations have been collected in $250 \mathrm{ml}$ soft low density polyethylene bottles washed with dilute hydrochloric acid prior to each cruise. They are kept refrigerated if the analysis is carried onboard, as is common in the spring, but frozen for analysis ashore as is common in the other seasons. In spring and summer, samples from the surface layer, 0-60 m, are syringe filtered through a $0.45 \mu \mathrm{m}$ Whatman PURADISC syringe filter to avoid turbidity blank effects, particularly on phosphate. Samples from deeper water are not filtered. Prior to 1987 a single channel Technicon AutoAnalyzer II was used for nitrate and silicate and a manual method for phosphate (Murphy and Riley, 1962). A Chemlab three channel autoanalyzer has been used since 1987, set up for determinations of dissolved phosphate, nitrate and silicate. The methods were those described by Grasshoff (Grasshoff, 1970) except for phosphate were a modified version of the Murphy and Riley method was automated (Murphy and Riley, 1962). A series of 5 working standards is prepared with each batch of samples and the response fitted to concentration with a 3rd order polynomial regression.

\subsubsection{Nutrient analysis quality control}

To assess the accuracy of the nutrient methods and procedures we have participated in, and subscribed to, the QUASIMEME laboratory QC programme and received since 1993 test materials for analysis twice a year (Wells et al., 1997). In QUASIMEME the laboratory performance is expressed with a $z$-score where $|z|<2$ is considered as acceptable results and where $\mathrm{z}$ is the difference between the laboratory result and the assigned value divided by the total error (Cofino and Wells, 1994). The test material concentrations have been variable over the years, sometimes been well above the range observed at the time series locations. We therefore prefer to express the MRI long term nutrient analyses performance on the basis of the differences between reported and assigned concentrations rather than $\mathrm{z}$-scores as these differences are directly comparable to the analytical uncertainty (Fig. 2). The average difference of MRI reported values for nitrate (Fig. 2a) from 1993-2008 is $-0.12 \mu \mathrm{mol} / 1$ (standard deviation $=0.16 \mu \mathrm{mol} / 1, n=28$ ), for phosphate (Fig. 2b) it is $-0.02 \mu \mathrm{mol} / 1$ (standard deviation $=0.02 \mu \mathrm{mol} / 1, n=28$ ). From 1996 silicate has been 

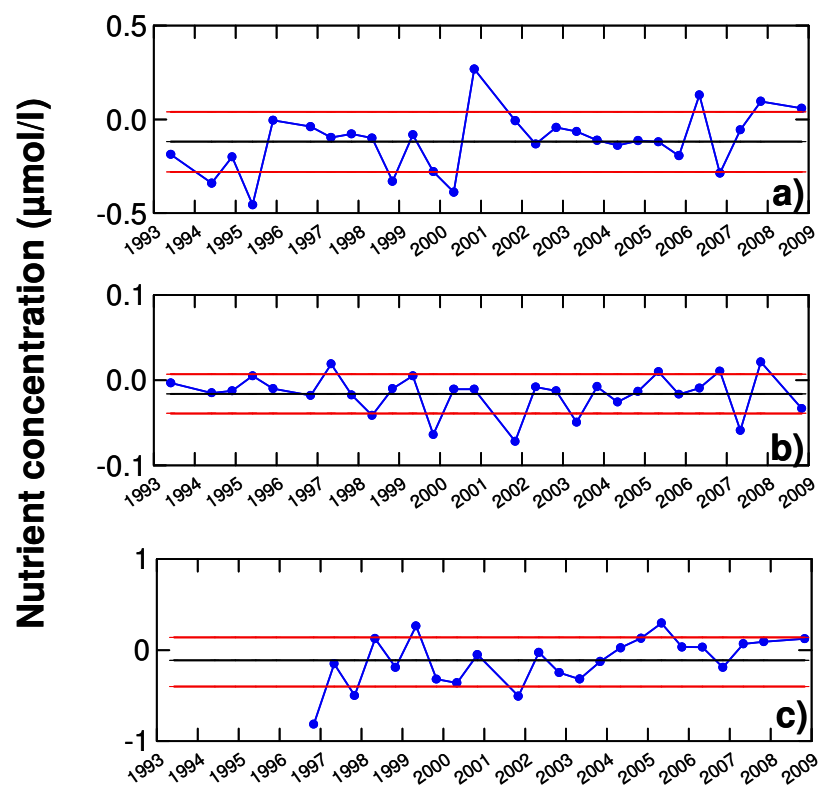

Figure 2. Average MRI-IS differences of (a) nitrate, (b) phosphate and (c) silicate concentrations (in $\mu \mathrm{mol} / \mathrm{l}$ ) from assigned values in QUASIMEME sea water test materials 1993-2008 (silicate from 1996). The overall long term mean deviations are shown with black slashed lines and their standard deviations are shown with a red dotted line.

measured (Fig. 2c) and the average deviation is $-0.11 \mu \mathrm{mol} / \mathrm{l}$ (standard deviation $=0.27 \mu \mathrm{mol} / \mathrm{l}, n=23$ ). Comparing these differences to the highest nutrient concentrations found on the time series stations yields less than $1.5 \%$ error for nitrate, $3.5 \%$ for phosphate and $2.5 \%$ for silicate.

In addition, a laboratory reference material, LRM (Aminot and Kérouel, 1998), is regularly produced, assessed and compared to QUASIMEME materials. The LRM has nutrient concentrations within the range found for the regional seawater and samples of the LRM are run with each sample batch. Results from these measurements are indicative of the precision and accuracy of the daily procedures. The LRM results are generally within accepted limits, $\pm 0.2 \mu \mathrm{mol} / 1$ for nitrate and silicate, $\pm 0.03 \mu \mathrm{mol} / 1$ for phosphate. Corrections based on the LRM results need rarely to be applied but the results do occasionally give cause for re-running samples.

\subsection{Partial pressure of carbon dioxide in seawater}

From 1983 to spring 1993, samples for $p \mathrm{CO}_{2}$ were collected onboard by recirculating $500 \mathrm{ml}$ marine air in a closed system through a bubbler immersed in a 41 surface seawater sample. The equilibrated gas was isolated and sealed in a $300 \mathrm{ml}$ glass flask equipped with a stopcock at each end and shipped for analysis at Lamont-Doherty Earth Observatory (LDEO) by means of gas chromatography. Air samples

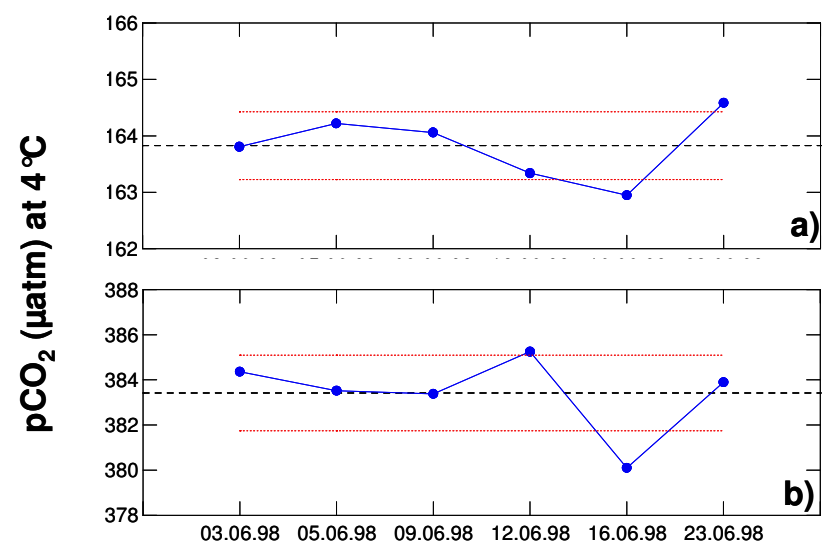

Figure 3. Results of $p \mathrm{CO}_{2}$ sample storage experiment. Average $p \mathrm{CO}_{2}$ ( $\mu$ atm at $4{ }^{\circ} \mathrm{C}$ ) in (a) samples from $5 \mathrm{~m}$ depth, and (b) samples from $200 \mathrm{~m}$ depth. The average concentrations for the storage experiment are shown with a black slashed line and their standard deviations are shown with red dotted lines.

were also collected in $300 \mathrm{ml}$ glass flasks by suction using a hand pump and were analysed the same way. The gas chromatograph was calibrated using air- $\mathrm{CO}_{2}$ gas mixtures which had been analysed by C. D. Keeling of the Scripps Institution of Oceanography. The procedure changed after mid year 1993. Then $500 \mathrm{ml}$ seawater samples for $p \mathrm{CO}_{2}$ were brought back to MRI in screw caped Pyrex bottles, inoculated with saturated $\mathrm{HgCl}_{2}$ solution (400 microliters) and kept in dark cold storage until analyzed. Their $p \mathrm{CO}_{2}$ values were determined at a known temperature and pressure using the bubble-type equilibrator system coupled with a gas chromatograph (Chipman et al., 1993), which was calibrated with three air- $\mathrm{CO}_{2}$ mixtures tied to the Keeling standards. The $p \mathrm{CO}_{2}$ was measured in the stored sea water samples generally within 14 days after the samples were collected at sea. The $p \mathrm{CO}_{2}$ data are not included in the merged CARINA data products, but are included in the individual cruise file available at http://cdiac.ornl.gov/oceans/CARINA/ Carina_inv.html.

\subsubsection{Storage experiment of $p \mathrm{CO}_{2}$ samples}

The effects of sample storage were evaluated at MRI by collection of two sets of 12 paired samples during spring bloom, 2 June 1998 in the Iceland Sea at $68^{\circ} \mathrm{N}, 18.8^{\circ} \mathrm{W}$. One set was from the surface $\left(t=1.83^{\circ} \mathrm{C}\right)$ and the other from $200 \mathrm{~m}\left(t=1.05^{\circ} \mathrm{C}\right)$, well below the euphotic layer. Duplicate samples were analysed ashore over the period 3 to 23 June (Fig. 3). The average concentration for the storage experiment was $163.8 \mu \mathrm{atm}$ at $5 \mathrm{~m}$ depth (s.d. $0.6 \mu \mathrm{atm}$, $n=6$ ) and $383.4 \mu \mathrm{atm}$ at $200 \mathrm{~m}$ depth (s.d. $1.7 \mu \mathrm{atm}$, $n=6$ ). The change with time of $p \mathrm{CO}_{2}$ in the surface samples and $200 \mathrm{~m}$ samples were $-0.006 \pm 0.05 \mu \mathrm{atm} \mathrm{d} \mathrm{d}^{-1}$ and $-0.06 \pm 0.08 \mu \mathrm{atm} \mathrm{d} \mathrm{d}^{-1}$ respectively, and was found to be very 
small. This indicates that sample storage of up to three weeks has insignificant influence on $p \mathrm{CO}_{2}$ and that the overall precision of the $p \mathrm{CO}_{2}$ determinations is better than $\pm 2 \mu \mathrm{atm}$.

\subsection{Dissolved inorganic carbon}

Total dissolved inorganic carbon $\left(\mathrm{TCO}_{2}\right)$ has been determined in $\mathrm{HgCl}_{2}$-preserved samples by coulometry (Chipman et al., 1993) using at LDEO the Coulometrics CM-5010 instrument. $\mathrm{HgCl}_{2}$ was found to be an effective preservation agent for $\mathrm{TCO}_{2}$ in seawater samples in tightly sealed bottles stored up to 7 months (Takahashi et al., 1970). Prior to 1991 the samples were analysed at LDEO where the coulometer was calibrated using three different methods: a) with weighed quantities of clear Iceland spar $\left(\mathrm{CaCO}_{3}\right)$, b) with weighed quantities of heat treated $\mathrm{Na}_{2} \mathrm{CO}_{3}$, and c) volumetrically determined $\mathrm{CO}_{2}$ gas (Takahashi et al., 1985). These calibrations were consistent with Keeling's manometric values as demonstrated by Wong (1970) using Keeling's manometric system. The overall precision in the period 1983 to 1990 is estimated as $\pm 4 \mu \mathrm{mol} \mathrm{kg}{ }^{-1}$ (Takahashi et al., 1985). As demonstrated extensively through the WOCE Program, the gas loop calibration method yielded $\mathrm{TCO}_{2}$ values consistent with those in the Dickson reference waters, which were tied to the Keeling's manometric system (Rubin et al., 1998; Takahashi et al., 2006). From 1991 the coulometric determinations (using an improved Coulometrics Model CM-5011) were performed at MRI where the coulometer was calibrated using $99.998 \% \mathrm{CO}_{2}$ gas in fixed volume gas loops at known pressure and temperature (Chipman et al., 1993).

The Iceland Sea time series $\mathrm{TCO}_{2}$ data were assesed as a part of the Nordic Seas CARINA data (Olsen, 2009). They were not included in the crossover and inversion analyses but it was concluded on the basis of nitrate- $\mathrm{TCO}_{2}$ relations that the $\mathrm{TCO}_{2}$ data "appeares reasonable" (Olsen, 2009).

\subsection{1 $\mathrm{TCO}_{2}$ quality control}

Accuracy of the $\mathrm{TCO}_{2}$ determinations at MRI is maintained since 1992 by comparison of results with sea water Certified Reference Material (CRM) calibrated and supplied by Dr. Andrew G. Dickson of the Scripps Institution of Oceanography. The evaluation of the CRM results indicated a systematic error of about $-4.7 \pm 2.0 \mu \mathrm{mol} \mathrm{C} \mathrm{kg}^{-1}$ in 212 CRM determinations. In 1999 the coulometer system gas loop volumes were redetermined by gravimetry and the systematic error ascribed to errors in the gas loop volumes. A correction multiplier of 1.0029 was hence applied to all results from analyses in the 1991-1998 period. The CRM results representing this period are shown in Fig. 4. Due to instrument problems there were no $\mathrm{TCO}_{2}$ analyses of samples or CRMs in 1999 and 2000. Samples collected in this period were analysed in 2001 and 2002. The samples were all spiked with $\mathrm{HgCl}_{2}$, stored refrigerated at

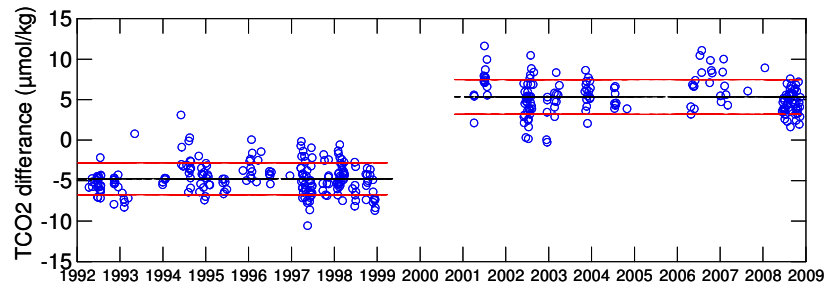

Figure 4. Results of MRI $\mathrm{TCO}_{2}$ determinations in Dickson's sea water reference materials (CRMs) in two periods 1992-1998 and 2001-2008. The average differences (MRI-CRM) are shown as black slashed lines and their standard deviations are shown with red dotted lines.

a stable temperature, $4{ }^{\circ} \mathrm{C}$, and in darkness. In 2001 the loop volume correction was taken account of in the $\mathrm{TCO}_{2}$ analysis software and the coulometer was factory serviced and recalibrated prior to commencement of analyses. The samples analysed from 2001 to 2008 were compared with CRMs run concurrently and adjustments made on the basis of the comparisons. The CRM results from 2001 to 2008 are also shown in Fig. 4. In 169 CRM determinations in this period, another systematic difference of about $+5.3 \pm 2.1 \mu \mathrm{mol} \mathrm{C} \mathrm{kg}^{-1}$ is evident. The cause was most likely a shift in the coulometer electronic calibration settings. Factory service in 2009 showed that the instrument had been out of electronic factory specifications. Thus all the time series $\mathrm{TCO}_{2}$ results have been adjusted by comparison with CRMs.

The precision of the $\mathrm{TCO}_{2}$ determinations at MRI is estimated from the standard deviation of the analysis of individual CRM batches. It ranges from 1.4 to $2.3 \mu \mathrm{mol} \mathrm{kg}{ }^{-1}$ for the period 1993 to 2008 based on 382 CRM determinations in 13 batches. The average is $1.85 \mu \mathrm{mol} \mathrm{kg}{ }^{-1}$ which rounds to $\pm 2 \mu \mathrm{mol} \mathrm{kg}{ }^{-1}$. Since all the time series $\mathrm{TCO}_{2}$ data are tied to CRMs, as described above, we estimate the overall accuracy as $\pm 2 \mu \mathrm{mol} \mathrm{kg}{ }^{-1}$, the uncertainty in the CRM determinations.

\section{Summary}

The ways and means of assembling and quality controling the Irminger Sea and Iceland Sea time-series biogeochemical data are described. These stations are in relatively shallow, but oceanographically important locations. Compared to the CARINA criteria, depth $>1500 \mathrm{~m}$, IRM-TS could not be included in secondary QC and the IS-TS only in a limited way. However, with the information provided here, the quality of the data can be assessed e.g. on the basis of the results obtained with the use of reference materials.

\section{Data access}

The whole CARINA database set is published at http://cdiac. ornl.gov/oceans/CARINA/Carina_inv.html. It contains 188 individual cruise files in comma-separated, WHPO exchange 
format. Condensed metadata are contained in the header of each data file. In addition, the CARINA database contains three merged, comma-separated data files with the data products. These files are divided into the three geographical regions of CARINA. No special software is needed to access the data, but software for MATLAB users is offered to facilitate reading of the data.

Acknowledgements. The authors thank all colleagues at the Marine Research Institute in Iceland, who have cooperated and assisted in the time series work in its course since 1983. John Goddard and Dave Chipman of LDEO were instrumental during the early stage. This work is supported by the European Community Sixth Framework Programme CARBOOCEAN IP, Marine carbon sources and sinks assessment Contract no. 511176. T. T. is supported by a grant (NAO30AR4320179P27) from US NOAA.

Edited by: T. Tanhua

\section{References}

Aminot, A. and Kérouel, R.: Pasteurization as an alternative method for preservation of nitrate and nitrite in sea water samples, Mar. Chem., 61, 203-208, 1998.

Carpenter, J. H.: The Chesapeake Bay Institute technique for the Winkler oxygen method, Limnol. Oceanogr., 10, 141-143, 1965.

Chipman, D., Marra, J., and Takahashi, T.: Primary production at $47^{\circ} \mathrm{N}$ and $20^{\circ} \mathrm{W}$ in the North Atlantic Ocean: A comparision between the ${ }^{14} \mathrm{C}$ incubation method and the mixed layer budget, Deep Sea Res. Pt. II, 40, 151-169, 1993.

Cofino, W. P. and Wells, D. E.: Design and evaluation of the QUASIMEME inter-laboratory performance studies: A test case for robust statistics, Mar. Pollut. Bull., 29, 149-158, 1994.

Grasshoff, K.: A simultaneous multiple channel system for nutrient analysis in seawater with analog and digital data record, Technicon Qtrly., 3, 7-17, 1970.

Hansen, B. and Østerhus, S.: North Atlantic-Nordic Seas exchanges, Prog. Oceanogr., 45, 109-208, 2000.

Hátún, H., Sandø, A., Drange, H., and Bentsen, M.: Seasonal to decadal temperature variations in the Faroe-Shetland inflow waters, in: The Nordic Seas: An integrated Perspective, edited by: Drange, H., Dokken, T., Furevik, T., Gerdes, R., and Berger, W., American Geophysical Union, Washington, DC, 239-250, 2005a.

Hátún, H., Sandø, A. B., Drange, H., Hansen, B., and Valdimarsson, H.: Influence of the Atlantic Subpolar Gyre on the thermohaline circulation, Science, 309, 1841-1844, 2005b.

Key, R. M., Tanhua, T., Olsen, A., Hoppema, M., Jutterström, S., Schirnick, C., van Heuven, S., Kozyr, A., Lin, X., Velo, A., Wallace, D. W. R., and Mintrop, L.: The CARINA data synthesis project: introduction and overview, Earth Syst. Sci. Data Discuss., 2, 579-624, 2009,

http://www.earth-syst-sci-data-discuss.net/2/579/2009/.

Murphy, J. and Riley, J. P.: A modified single solution method for the determination of phosphate in natural waters, Anal. Chim. Acta, 27, 31-36, 1962.

Olafsson, J., Olafsdottir, S. R., Benoit-Cattin, A., Danielsen, M., Arnarson, T. S., and Takahashi, T.: Rate of Iceland Sea acidification from time series measurements, Biogeosciences, 6 , 2661-2668, 2009,

http://www.biogeosciences.net/6/2661/2009/.

Olafsson, J. and Olsen, A.: Nordic Seas nutrients data in CARINA, Earth Syst. Sci. Data Discuss., 3, 55-78, 2010, http://www.earth-syst-sci-data-discuss.net/3/55/2010/.

Olsen, A.: Nordic Seas total dissolved inorganic carbon data in CARINA, Earth Syst. Sci. Data, 1, 35-43, 2009, http://www.earth-syst-sci-data.net/1/35/2009/.

Olsen, A., Key, R. M., Jeansson, E., Falck, E., Olafsson, J., van Heuven, S., Skjelvan, I., Omar, A. M., Olsson, K. A., Anderson, L. G., Jutterström, S., Rey, F., Johannessen, T., Bellerby, R. G. J., Blindheim, J., Bullister, J. L., Pfeil, B., Lin, X., Kozyr, A., Schirnick, C., Tanhua, T., and Wallace, D. W. R.: Overview of the Nordic Seas CARINA data and salinity measurements, Earth Syst. Sci. Data, 1, 25-34, 2009, http://www.earth-syst-sci-data.net/1/25/2009/.

Peng, T.-H., Takahashi, T., Broecker, W. S., and Ólafsson, J.: Seasonal variability of carbon dioxide, nutrients and oxygen in the northern North Atlantic surface water: Observations and a model, Tellus, 39B, 439-458, 1987.

Rubin, S., Goddard, J. G., Chipman, D. W., Takahashi, T., Sutherland, S. C., Reid, J. L., Swift, J. H., and Talley, L. D.: Carbon dioxide, hydrographic, and chemical data obtained in the South Pacific Ocean (WOCE section p16a/p17a, p17e/p19s, and p19c, R/V Knorr, October 1992-April 1993) ORNL/CDIAC-150, NDP-065, 1998.

Stefánsson, U.: North Icelandic Waters, Rit Fiskideildar, 3, 1-269, 1962.

Takahashi, T., Weiss, R. F., Culberson, C. H., Edmond, J. M., Hammond, D. E., Wong, C. S., Li, Y.-H., and Bainbridge, A. E.: A carbonate chemistry profile at the 1969 GEOSECS intercalibration station in the eastern Pacific Ocean, J. Geophys. Res., 75, 7648-7666, 1970.

Takahashi, T., Ólafsson, J., Broecker, W. S., Goddard, J., Chipman, D. W., and White, J.: Seasonal variability of the carbon-nutrient chemistry in the ocean areas west and north of Iceland, Rit Fiskideildar, 9, 20-36, 1985.

Takahashi, T., Millero, F., Key, R., Chipman, D., Peltola, E., Rubin, S., Sweeney, C., and Sutherland, S.: Determination of carbon dioxide, hydrographic, and chemical parameters during the R/V Nathaniel B. Palmer cruise in the Southern Indian Ocean (WOCE section s04i, 3 May-4 July, 1996) ORNL/CDIAC-150, NDP-086 2006.

Tanhua, T., Steinfeldt, R., Key, R. M., Brown, P., Gruber, N., Wanninkhof, R., Perez, F., Körtzinger, A., Velo, A., Schuster, U., van Heuven, S., Bullister, J. L., Stendardo, I., Hoppema, M., Olsen, A., Kozyr, A., Pierrot, D., Schirnick, C., and Wallace, D. W. R.: Atlantic Ocean CARINA data: overview and salinity adjustments, Earth Syst. Sci. Data, 2, 17-34, 2010, http://www.earth-syst-sci-data.net/2/17/2010/.

Wells, D. E., Aminot, A., De Boer, J., Cofino, W., Kirkwood, D., and Pedersen, B.: A review of the achievements of the EU project 'QUASIMEME' 1993-1996, Mar. Pollut. Bull., 35, 3-17, 1997.

Wong, C. S.: Quantitative analysis of total carbon dioxide in seawater: A new extraction method, Deep-Sea Res., 17, 9-19, 1970. 